\title{
Marcas e indicadores humorísticos en las narraciones escritas de niños y niñas de 8, 10 y 12 años en español Propuesta tipológica
}

\author{
Larissa Timofeeva-Timofeev y Leonor Ruiz-Gurillo \\ Universidad de Alicante
}

\begin{abstract}
Este trabajo presenta una propuesta tipológica de marcas e indicadores humorísticos (Ruiz-Gurillo 2012, 78-86) que actúan como soportes empíricos en la investigación en torno al humor verbal infantil. Nuestra clasificación se fundamenta en el análisis de 448 narraciones humorísticas, escritas por escolares de 8,10 y 12 años procedentes de 5 centros educativos de la provincia de Alicante (Timofeeva-Timofeev 2017). Asimismo, es la base del etiquetaje pragmático del corpus CHILDHUM, actualmente en construcción, compuesto por estas y otras narraciones procedentes de diversas partes de España. La observación en el corpus de cómo evoluciona el uso de marcas e indicadores humorísticos a lo largo de las franjas etarias examinadas revela pautas de desarrollo de la competencia humorística y la metalingüística, aportando datos empíricos nuevos que no son accesibles desde la perspectiva íntegramente psicológica.
\end{abstract}

Palabras clave: edad de 8 a 12 años, marcas e indicadores humorísticos, competencia humorística, desarrollo metalingüístico

\section{Introducción}

La definición del humor en la que se sostiene este estudio se inserta en la corriente teórica que considera la incongruencia como elemento esencial de una manifestación cómica. Ello no significa que toda incongruencia dé lugar a humor, pero sí que la experiencia humorística intencional busca la generación de una incongruencia como su punto de apoyo. Por tanto, y sin entrar en debates más complejos y amplios sobre el tema, defenderemos en este estudio la idea de que: 
en el germen del humor se encuentra la incongruencia que se resuelve produciendo un placer y una fruición intelectuales que asociamos al humor. En otras palabras, el humor se presenta como un hecho pragmático que se origina cuando dos o más interpretaciones incompatibles de la situación se activan y derivan, como consecuencia, en una generación de inferencias alternativas, necesarias para conseguir un sentido adecuado. (Timofeeva-Timofeev y Ruiz-Gurillo 2018)

Desde este punto de partida, queremos observar cómo evoluciona la competencia humorística verbal a través de tres franjas etarias que abarca el corpus CHILDHUM. Dicho corpus, en pleno proceso de expansión, integrará narraciones humorísticas escritas por niños y niñas de 8, 10 y 12 años procedentes de diversos centros educativos de España, y estará etiquetado de acuerdo a un sistema de marcas e indicadores humorísticos cuya base desarrollamos en este trabajo. Tal procedimiento nos permite contemplar dichas marcas e indicadores como elementos mesurables que pueden indicar pautas madurativas en cuanto a la competencia humorística, metalingüística - especialmente, metapragmática y metatextual - o el desarrollo psicosocial concierne.

Para exponer nuestra propuesta tipológica de marcas e indicadores humorísticos empleados en las narraciones del corpus, en primer lugar, en el apartado 2 perfilaremos un breve entorno teórico de este estudio. A continuación, en 3 y 4 nos detendremos en los objetivos y en los aspectos metodológicos y procedimentales de nuestra investigación. En 5 se abordarán los resultados cuantitativos de los datos procesados cuyo análisis cualitativo se ofrecerá en 6. Finalmente, en el apartado 7 se presentarán las conclusiones de la investigación que incluyen el compendio de las marcas e indicadores humorísticos resultantes del análisis de nuestro corpus.

\section{Andamiaje teórico}

Si bien un hecho pragmático tan poliforme como el humor es resultado de la acción de varios factores concomitantes, es posible rastrear ciertas pautas y rasgos comunes en el comportamiento humorístico desde diversas perspectivas. Para los objetivos de este trabajo, hay dos puntos focales que debemos marcar como nuestras bases teóricas: el humor como competencia en desarrollo; y la evolución de la conciencia metalingüística como condición para el manejo de procedimientos lingüísticos al servicio del humor. Dichos procedimientos lingüísticos - denominados marcas e indicadores humorísticos - se convierten, por tanto, en instrumentos de medición empírica que los lingüistas podemos emplear en nuestro acercamiento al humor verbal. Por ello, encuadrar el análisis de las marcas e indicadores humorísticos en el contexto de desarrollo cognitivo y metalingüístico en 
el periodo de edad de nuestro interés resulta esencial para obtener una visión global y coherente de la producción humorística infantil.

En lo que sigue, pues, ofreceremos las principales claves teóricas acerca de las características de la competencia humorística (2.1) y de la conciencia metalingüística (2.2) a la edad de 8 a 12 años, para culminar el recorrido planteando las nociones de marcas e indicadores humorísticos como resortes empíricos de nuestra investigación (2.3).

\subsection{Desarrollo de la competencia humorística}

Unas líneas más arriba definíamos la incongruencia como factor nuclear del humor. Varios estudios más recientes apuntan que:

[i]ncongruity is not an essential element, if it is to be perceived as (always) the most important in achieving a humorous reaction. Instead, it is essential in the sense that without incongruity the specificity of a humor experience is missing.

$\left(\right.$ Forabosco 2008, 57) ${ }^{1}$

La misma idea parece subyacer al proceso de formación de la competencia humorística que se articula en torno a la adquisición y un paulatino desarrollo y consolidación de la capacidad de aprehender y de crear la incongruencia.

Diversas investigaciones en psicología evolutiva muestran que la noción de incongruencia emerge a una edad muy temprana, pues ya bebés menores de 7 meses se ríen mucho más ante un estímulo inesperado y sorpresivo que ante uno repetitivo (Cunningham 2005, 99). Dicho esto, es evidente que un control consciente y un uso reflexivo de las diversas técnicas creadoras de la incongruencia requiere madurez cognitiva y metalingüística, por lo que " $[\mathrm{t}]$ he intentional management of linguistic humour [...] appears to be a complex ability which is late to emerge" (Gombert 1992, 118).

McGhee (1979, 2002), en una propuesta ya clásica, establece 6 fases de desarrollo que atraviesa un niño hasta adquirir una competencia humorística completa (i.e., humor adulto). La primera - Stage o: Laughter without Humor, que se concibe como la fase de pre-humor y que abarca los primeros seis meses de vida del bebé - se relaciona con la adquisición de la capacidad de reír y de sonreír, aún sin la presencia del componente intencional, sino más bien como parte del desarrollo neuro-fisio-psicológico general. En la siguiente etapa - Stage 1: Laughter at the Attachment Figure, que dura de los 6 a los 15 meses de edad aproximadamente - la observación de los padres y cuidadores mientras realizan acciones

1. Consúltese a este respecto también Martin 2014, 2016; O’Shannon 2012; Meany, Clark and Laineste 2014, 10-12; Timofeeva-Timofeev 2017, 9. 
incongruentes con objetos diversos (como, por ejemplo, ponerse un calcetín en la cabeza, soplar en una botella o hacer aparecer y desaparecer las cosas de forma inesperada) se convierte en principal fuente de la risa. Por ello, este período marca el inicio en la comprensión de la incongruencia intencionada como promotor de disfrute y buen humor. En la fase siguiente - Stage 2: Treating an Object as a Different Object que se prolonga desde los 15 meses hasta 2-3 años de edad - el niño pasa de la observación a la acción y se aventura en el uso incongruente de los objetos por sí solo. Las acciones como ponerse un plato en la cabeza a modo de sombrero o utilizar un plátano como si fuera un teléfono surgen primero por imitación, si bien poco a poco aparecen actos propios que buscan provocar la risa de los presentes. A partir de los 3 y hasta los 4-5 años el pequeño cómico descubre que el humor puede apoyarse en procedimientos menos 'tangibles' como es el lenguaje. Las palabras denominan cosas y cualquier transgresión en esa denominación puede resultar hilarante. Este periodo, llamado Stage 3: Misnaming Objects or Actions, representa las primeras incursiones evidentes del niño en el mundo del humor verbal. Asimismo, llamar al perro 'gato' de manera deliberada, o el uso incipiente del léxico escatológico, son actuaciones que quebrantan las normas lingüísticas y sociales establecidas y, por tanto, reflejan la progresiva toma de conciencia de la dimensión social del humor (cfr. Martin 2007, 239; Hoicka y Akhtar 2012; Timofeeva-Timofeev 2017, 10). El descubrimiento de las posibilidades que brinda el lenguaje para generar humor continúa en la siguiente etapa madurativa denominada Stage 4: Playing with Words. La incongruencia se persigue en un nivel más conceptual, pues ahora "ya no solo que el perro se llama 'gato', sino que además hace "mu" (Timofeeva-Timofeev 2017, 10). Tal discrepancia, no obstante, no se sustenta en los procedimientos lógicos que subyacen a buena parte de chistes o juegos de palabras, sino que es meramente fónica o visual (cfr. McGuee 2002; Lyon 2006, 5; Martin 2007, 240). En la última fase de la clasificación de McGhee - Stage 5: Riddles and Jokes - que abarca la franja etaria de 6 a 11 años aproximadamente, se completa la formación de la competencia humorística con la adquisición de las habilidades cognitivas y metalingüísticas necesarias para la interpretación y generación del humor basado en los dobles sentidos, ambigüedades y otras formas complejas del pensamiento asociadas al razonamiento inferencial (Piaget 1972, 1987). Es cierto que la caracterización de este periodo en la propuesta de McGhee ofrece varios puntos debatibles, pues no refleja fehacientemente la variedad de cambios madurativos de diversa índole que experimentan los niños y las niñas a lo largo de esta franja. Asimismo, resulta cuestionable la asunción de que a partir de los 11-12 años ya se posee la competencia humorística asimilable a la de un adulto.

Todas estas zonas inciertas nos motivan a poner el foco investigador precisamente en esta etapa etaria, abordando la cuestión desde una perspectiva lingüís- 
tica. El análisis de las narraciones humorísticas escritas por los niños y las niñas de 8 a 12 años de nuestro corpus permite organizar el vasto compendio de los elementos verbales a los que recurren nuestros informantes para construir sus historias. Siguiendo los presupuestos del modelo de McGhee (2002), las tres franjas etarias de nuestra investigación se sitúan en el estadio 5 y presentarían, por tanto, un amplio dominio de técnicas lingüísticas que subyacen a la interpretación y producción del humor. Los participantes más mayores (i.e., 12 años) mostrarían, incluso, un humor equiparable al adulto. En este contexto, el análisis de las marcas e indicadores del humor que ofrecemos en este trabajo se antoja sumamente relevante por su capacidad para reforzar o refutar los planteamientos teóricos iniciales, al menos en su aplicación al español. Asimismo, estas marcas e indicadores actúan en nuestra investigación como puentes que nos permiten conectar epistemológicamente el desarrollo metalingüístico y la habilidad productiva del humor.

\subsection{Las competencias metapragmática y metatextual de 8 a 12 años}

Dado que nuestro objeto de estudio son las técnicas lingüísticas que emplean los escolares de 8, 10 y 12 años para generar historias humorísticas escritas, dentro de la extensión de la competencia metalingüística, nuestra atención se tiene que centrar especialmente en dos subcompetencias. Atendiendo al modelo de desarrollo metalingüístico de Gombert (1992), las subcompetencias metapragmática y metatextual sobresalen en importancia en el contexto de este trabajo. La primera de ellas, la subcompetencia metapragmática, por abarcar el complejo hecho del humor verbal. El propio Gombert señala que " $\mathrm{t}]$ he detection of linguistic incongruities is an activity which requires metapragmatic abilities" (Gombert 1992, 119). Una visión global de la subcompetencia metatextual, a su vez, ha de ser tenida en cuenta al caracterizar las producciones escritas de nuestros informantes.

La subcompetencia metapragmática se refiere a un uso consciente y reflexivo que se hace del lenguaje o, lo que es lo mismo, que cada acto verbal supone un control intencional de los diversos parámetros lingüísticos que determinan la eficacia del mensaje y su concordancia con la situación extralingüística (cfr. Crespo y Alvarado 2010, 95). Gombert $(1992,94)$ afirma que mientras que "pragmatic abilities permit the effective use of language in its (social) context, [...] the metapragmatic abilities allow the comprehension and control of this use".

Los niños adquieren dicho control discursivo como parte de su desarrollo metalingüístico y, como muchos estudios ponen de manifiesto, existe una proporción directa entre la edad y el conocimiento metapragmático (cfr. Gombert 1992, 1997; Doherty y Perner 1998; Crespo y Alfaro 2009; Collins et al. 2014). En este sentido, los niños atraviesan una serie de etapas madurativas hasta alcanzar a dominar, a la edad de 11-12 años, los diversos aspectos de la relación lengua- 
contexto. Gombert (1992) propone la existencia de cuatro etapas de desarrollo metapragmático que se plantean en paralelo a las fases de desarrollo cognitivo de Piaget (1972). Así, en la primera etapa de adquisición de habilidades lingüísticas básicas (hasta los 2 años), el niño adquiere las principales destrezas lingüísticas tanto de compresión como de producción. Desde los 2 a los 7 años los infantes se encuentran en la fase de control epipragmático, caracterizada por la incipiente conciencia de la complejidad de la relación entre lo lingüístico y lo contextual, pero por la incapacidad todavía de correlacionar adecuadamente ambas informaciones. Ello se refleja en fallos ocasionales, especialmente en el manejo de formas figuradas, así como en la incompetencia de definir explícitamente sus actuaciones pragmáticas. A partir de los 7 años los niños aprenden a discernir entre las informaciones lingüística y contextual, y a conjugarlas adecuadamente. Adquieren, por tanto, la conciencia metapragmática que les capacita para ejercer control sobre sus decisiones lingüístico-contextuales, así como para explicar cómo se lleva a cabo dicho control. El proceso se completa en una cuarta fase a partir de unos 12 años en la que la competencia metapragmática se automatiza, esto es, "becomes automated and occurs without conscious attention, except when some aspect of language is deliberately brought into consciousness for explicit attention" (Myhill 2012, 252).

La franja de edad de 8 a 12 años que abarcamos en este estudio constituye un periodo crucial marcado por el paso del comportamiento epipragmático al metapragmático. Asimismo, como ya señalábamos en trabajos anteriores (TimofeevaTimofeev 2014, 2017), las cuatro fases de Gombert

representan un proceso de evolución “acumulativa” en la que los niños no abandonan la fase anterior para entrar en la siguiente, sino que van adquiriendo las nuevas habilidades que se unen a las previamente alcanzadas en términos cuantitativos y cualitativos. Dicho de otro modo, el paso por las diversas fases de desarrollo va asociado al cada vez mayor número de habilidades, estrategias y técnicas metapragmáticas; y, a la vez, se produce un "modelaje" cualitativo de las competencias a partir de la interacción entre las experiencias metapragmáticas anteriores y las nuevas.

(Timofeeva-Timofeev 2017, 8)

Por este motivo, nuestros informantes muestran unos comportamientos verbales ajustados a su nivel madurativo, pero no se debe descartar la presencia de procedimientos propios de las fases de desarrollo anteriores.

Dado que trabajamos con producciones escritas, conviene ofrecer, asimismo, una visión general de la competencia metatextual. Como subraya Verschueren $(2000,444)$ "writing is a verbal activity involving a generally high degree of consciousness in the making of linguistic choices (in comparison to more spontaneous oral interaction)". Por ello, la habilidad metatextual - que incluye un control cons- 
ciente de aspectos tales como la coherencia, la cohesión o la estructura textual de un enunciado, especialmente relevantes en la escritura (Gombert 1992, 121; Myhill 2012, 252, 260, 264) - es la última en adquirirse. Se explica así la todavía importante presencia de la 'oralidad' - especialmente en las narraciones de 8 años - pues los niños escriben como hablan, "sin realizar adaptaciones a la modalidad escrita" (Timofeeva-Timofeev 2017, 8; cfr. también Crespo, Benítez y Pérez 2010).

La Tabla 1 resume la perspectiva evolutiva de la competencia metapragmática del humor que hemos presentado y permite visualizar la situación de nuestros informantes. Dentro de este recuadro teórico analizaremos el uso de los diversos procedimientos lingüísticos - denominados marcas e indicadores humorísticos que los participantes de nuestro estudio han empleado en sus historias cómicas.

Tabla 1. Competencia metapragmática del humor

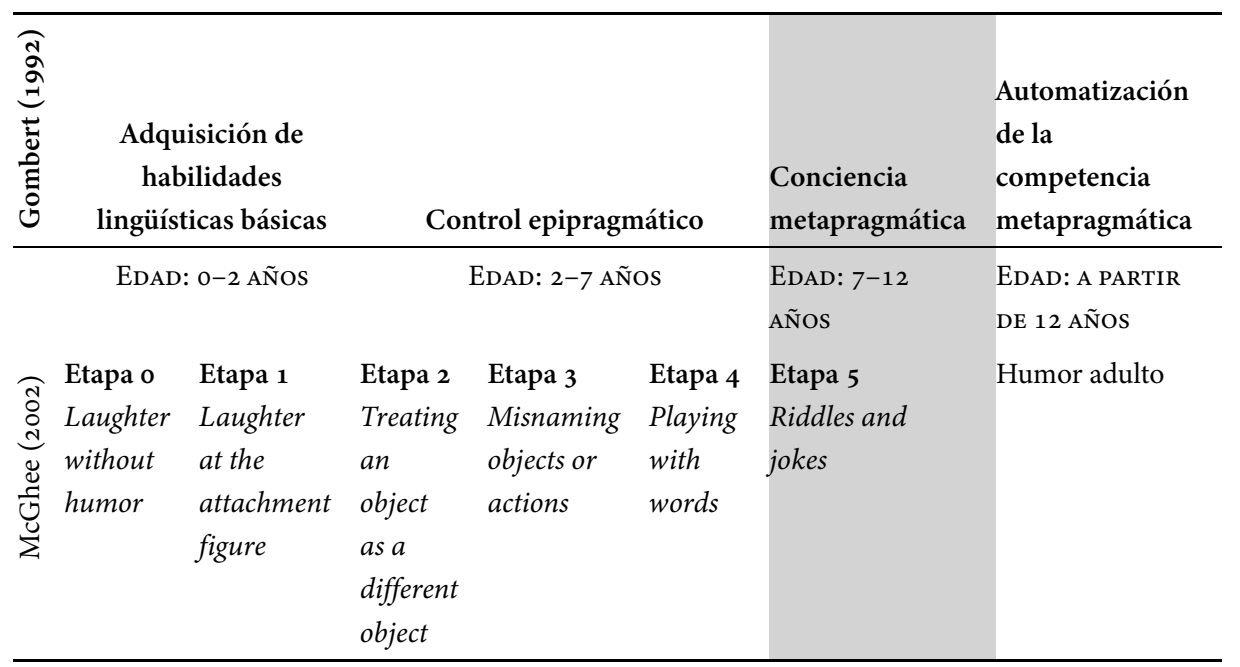

\subsection{Marcas e indicadores humorísticos como claves de desarrollo} metalingüístico

El joven escritor de nuestras narraciones emplea ya ciertos elementos lingüísticos con los que manifiesta su competencia humorística. Dichos elementos constituyen, por tanto, huellas metalingüísticas cuya identificación y análisis nos permite elaborar un cuadro tipológico que posibilite la correlación entre el desarrollo de las competencias (meta)lingüística y humorística.

Si bien es cierto que el estudio de marcas verbales del humor ya cuenta con cierta bibliografía (véase revisión en Burgers y Mulken 2017; Gironzetti 2017, entre otros), los diversos investigadores coinciden en que " $[\mathrm{t}]$ he mechanisms of keying and framing [of humor] are almost entirely unexplored” (Attardo 2017, 
12). La situación no es distinta para el caso del español, y el grupo GRIALE, ${ }^{2}$ en cuyo seno se desarrolla esta investigación, se erige como el principal exponente del estudio del humor verbal en esta lengua. En este sentido, GRIALE cuenta con un conjunto de trabajos dedicados al análisis de las claves lingüísticas del humor tanto en géneros propiamente humorísticos como no humorísticos (véase en especial Ruiz-Gurillo 2012, 2014, 2016; Alvarado 2016a, 2016b; Martínez Egido 2016). No obstante, las investigaciones acerca de su empleo en la población infantil, y más concretamente, en la franja etaria de 8 a 12 años, se limitan a trabajos recientes que han empleado el corpus CHILDHUM para su análisis (véase Timofeeva-Timofeev 2014, 2016, 2017; Santamaría Pérez 2017; Marimón Llorca 2017; Martínez Egido 2017; Ruiz-Gurillo 2017a, 2017b; Galindo Merino 2017).

Las investigaciones en torno al humor verbal en el marco de GRIALE nos han permitido diferenciar dos grupos de elementos lingüísticos que emplean los hablantes para señalar sus intenciones humorísticas. Por un lado, las marcas humorísticas que son componentes lingüísticos, paralingüísticos y extralingüísticos que ayudan a interpretar un determinado texto como humorístico. En el caso de este trabajo, al tratarse de textos escritos y que, además, son generados por niños y niñas, las marcas humorísticas se refieren en muchas ocasiones a elementos tipográficos, como la exclamación, la interjección, los puntos suspensivos o las risas. Asimismo, el uso de dibujos o pictogramas, como veremos en 3, actúa como pistas para la interpretación humorística. Por otro lado, los indicadores humorísticos son elementos lingüísticos que se convierten en humorísticos en un contexto determinado. Esto significa que, aunque estos elementos pueden actuar de modo no humorístico en otros contextos, en contextos humorísticos revelan la incongruencia que subyace al humor. En las narraciones infantiles objeto de estudio de este trabajo son ejemplos de indicadores los términos valorativos, la fraseología, la hipérbole o el estilo directo.

\section{Objetivos}

En el contexto investigador expuesto, los objetivos de este trabajo pueden resumirse en dos:

a. observar la evolución en el uso de marcas e indicadores humorísticos a lo largo de los tres periodos etarios - de 8, 10 y 12 años - en relación con el pro-

2. El Grupo de Investigación sobre la ironía y el humor en español de la Universidad de Alicante (GRIALE) aúna a lingüistas que desde la fundación del grupo en 2002 se han dedicado a desentrañar los mecanismos verbales que subyacen a la generación del humor. Para más información sobre GRIALE visítese su página web http://griale.dfelg.ua.es/. 
ceso de desarrollo de las competencias metalingüísticas (metapragmática y metatextual, especialmente) y el humor;

b. elaborar una tipología de marcas e indicadores humorísticos a partir de los procedimientos empleados por los participantes en nuestro estudio que sea útil en el futuro para el corpus CHILDHUM.

\section{Metodología}

Como hemos señalado en 1, la base empírica de este trabajo la constituyen las narraciones humorísticas que forman parte del corpus CHILDHUM - actualmente en construcción - que fueron escritas por niños y niñas de educación primaria. En lo que sigue, presentaremos sucintamente las características de los participantes del estudio, así como los procedimientos de recogida y procesamiento de datos.

\subsection{Participantes}

Para los objetivos de este trabajo han sido analizadas 448 historias humorísticas escritas por escolares de $2^{\circ}$ ( 8 años), $4^{\circ}$ (10 años) y $6^{\circ}$ (12 años) cursos de Educación Primaria, procedentes de 5 colegios - 4 públicos y 1 privado - de la provincia de Alicante. La Figura 1 recoge la distribución de los participantes en los tres grupos etarios:

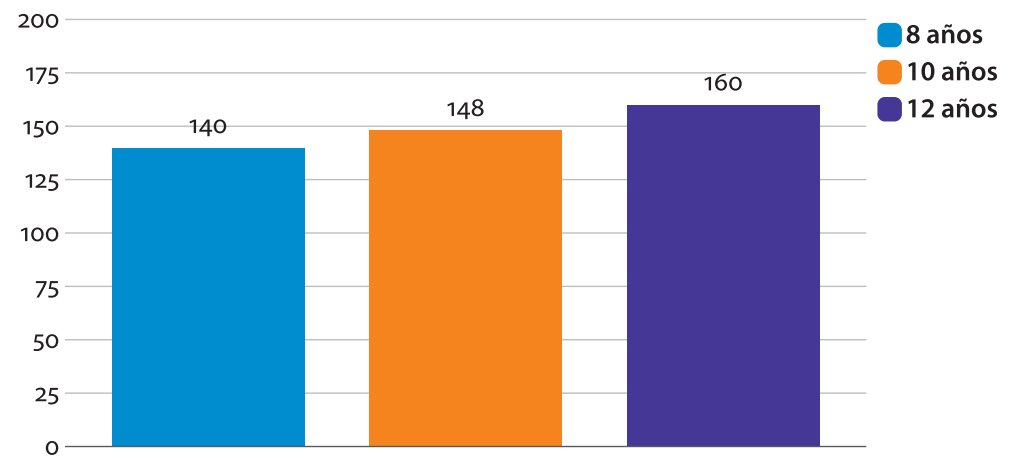

Figura 1. Distribución de los participantes en los tres grupos etarios

En cuanto a la distribución por género, la Tabla 2 refleja los datos para cada etapa de estudio que a continuación se ilustran en términos porcentuales en la Figura 2. 
Tabla 2. Distribución de participantes por género

\begin{tabular}{lcc}
\hline & Chicas & Chicos \\
\hline 8 años & 58 & 82 \\
10 años & 75 & 73 \\
12 años & 87 & 73 \\
\hline
\end{tabular}

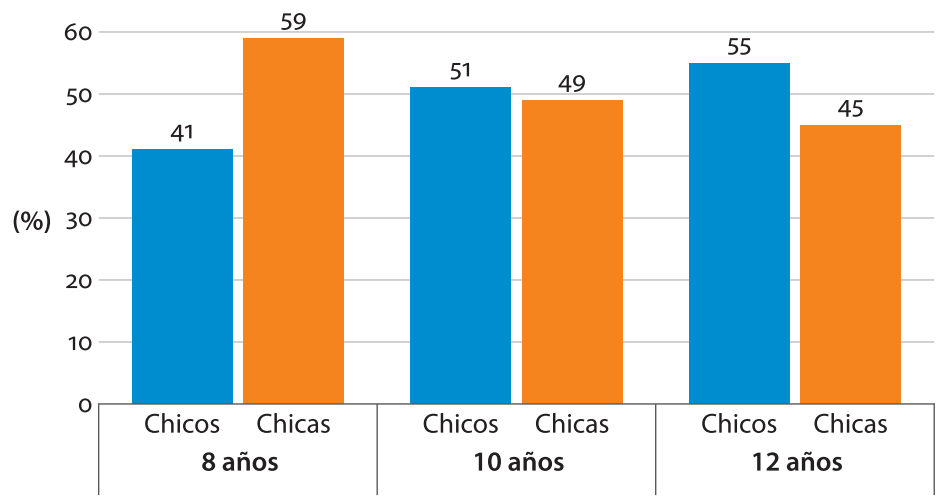

Figura 2. Porcentajes de distribución de participantes por género

\subsection{Procedimiento}

Las redacciones humorísticas objeto de este estudio fueron recogidas durante los cursos académicos 2012-2013 (10 años) y 2014-2015 (8 y 12 años). Los participantes de los tres grupos etarios escribieron un relato humorístico según un tema propuesto por el equipo investigador. La realización del ejercicio fue voluntaria y anónima, con las únicas indicaciones del sexo y la edad de los escolares.

El tema y el entorno narrativo de los relatos fue suministrado por los investigadores con el fin de no distraer a los participantes en la búsqueda de un tópico adecuado y de centrar su atención en el desarrollo de la historia en sí. Tal opción nos permitía, asimismo, homogeneizar las muestras y evitar que la elección más o menos acertada del tema determinara su carácter humorístico (cfr. TimofeevaTimofeev 2017, 15). De este modo, los escolares de 8 y 10 años escribieron sus relatos sobre el tema "Intercambio escolar en Marte", mientras que los participantes de 12 años lo hicieron sobre "Un día te conviertes en un insecto".

Una vez recogidas, las narraciones fueron etiquetadas con un código que incluye la información sobre la franja de edad, el curso de realización del ejercicio,

3. Para más detalles sobre los temas y el procedimiento de recogida y procesamiento de datos, véase Timofeeva-Timofeev 2014, 2017. 
la identificación del colegio, el sexo del/la participante y el número correlativo de la muestra. A continuación, se procedió a la lectura, el análisis y el vaciado de datos sobre el uso de los diversos elementos lingüísticos para generar el humor. Este proceso nos permitió obtener un compendio de marcas e indicadores humorísticos cuya tipología se presenta en este trabajo. Asimismo, dicha tipología nos posibilita crear un sistema de etiquetado que se está empleando en el corpus CHILDHUM, actualmente en elaboración.

\section{Resultados}

Los resultados cuantitativos que arroja nuestro corpus se presentan a través de las Figuras 3-8. Cabe advertir que para los objetivos de este trabajo se ha simplificado la representación cuantitativa de algunas marcas e indicadores que, no obstante, aparecen detalladas en la propuesta tipológica en 7. Así, por ejemplo, en las figuras relativas a las marcas humorísticas hemos unificado las diversas muestras simbólicas, si bien el etiquetado del corpus CHILDHUM contempla su consideración desglosada en pictográficos, con letras y numéricos (vid. 7). Por otro lado, la complejidad y la heterogeneidad en el uso de los distintos tipos de marcadores discursivos que revela nuestro corpus, exige un estudio independiente que sobrepasa los objetivos de este trabajo. Por ello, se ha optado por ofrecer un porcentaje que constituye la media de los diferentes tipos de marcadores usados sin indagar en las diferencias en su distribución de empleo.

En cuanto al apartado de los indicadores, se ha procedido a la simplificación numérica en relación con los procedimientos de paronimia / homonimia / homofonía, así como con los diversos tipos de formación de palabras, tanto afijal como otros. Entre los mecanismos retóricos constatados en nuestro corpus se han incluido en un grupo general de "otros procedimientos retóricos" aquellos que inicialmente no han sido computados cuantitativamente de manera independiente, aunque se han integrado como tales en el sistema del etiquetado definitivo de CHILDHUM (vid. la tipología en 7). Asimismo, en esta fase de procesamiento del corpus no hemos marcado de modo explícito las diversas variaciones diasistémicas, pero dado que sí hemos constatado su incidencia, se han incorporado a la tipología de indicadores humorísticos que recogemos en 7.

En relación con los porcentajes que aparecen en las Figuras 3-8, estos hacen referencia a la cantidad de narraciones que contienen una determinada marca o indicador, pero no reflejan la frecuencia de su uso por cada texto. Por tanto, los datos porcentuales se han calculado a partir de un total de 140 narraciones para 8 años; 148, para 10 años y 160, para 12 años (Figura 1). 


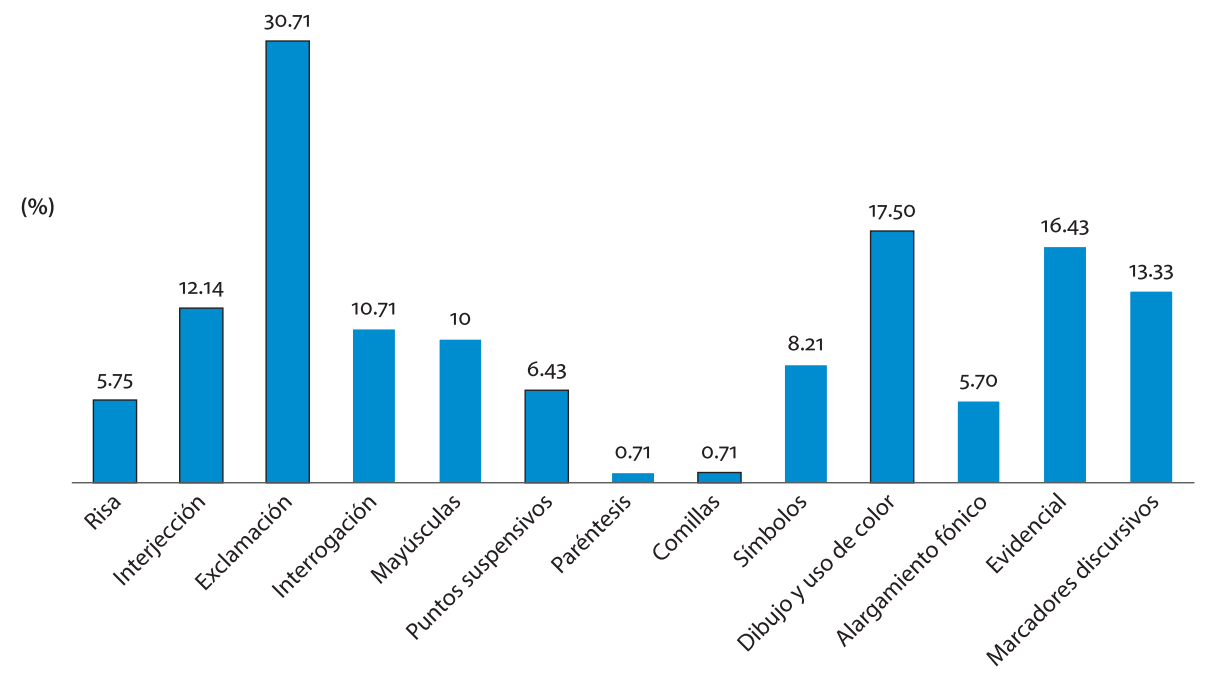

Figura 3. Tipología y porcentajes de marcas humorísticas en las narraciones de 8 años

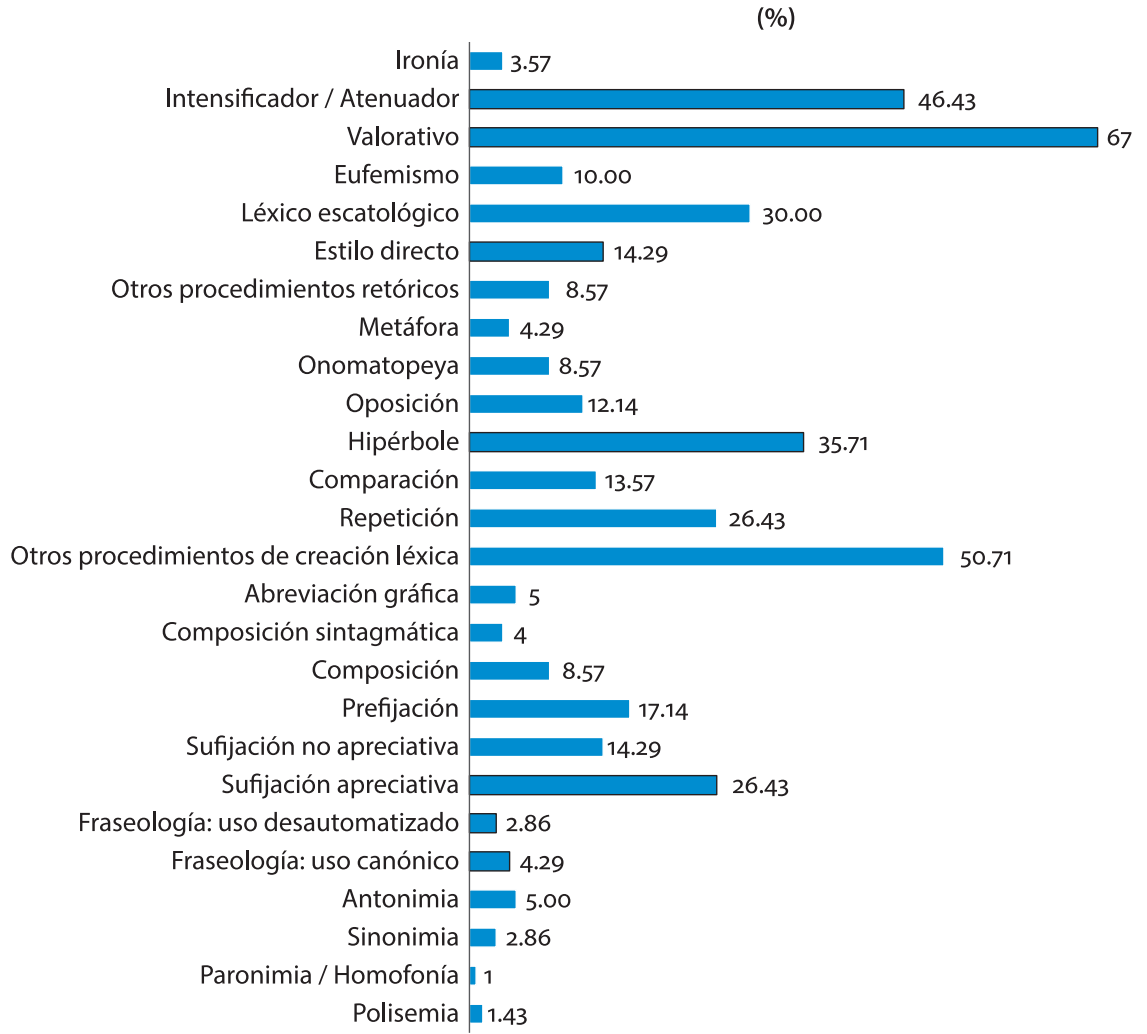

Figura 4. Tipología y porcentajes de indicadores humorísticos en las narraciones de 8 años 


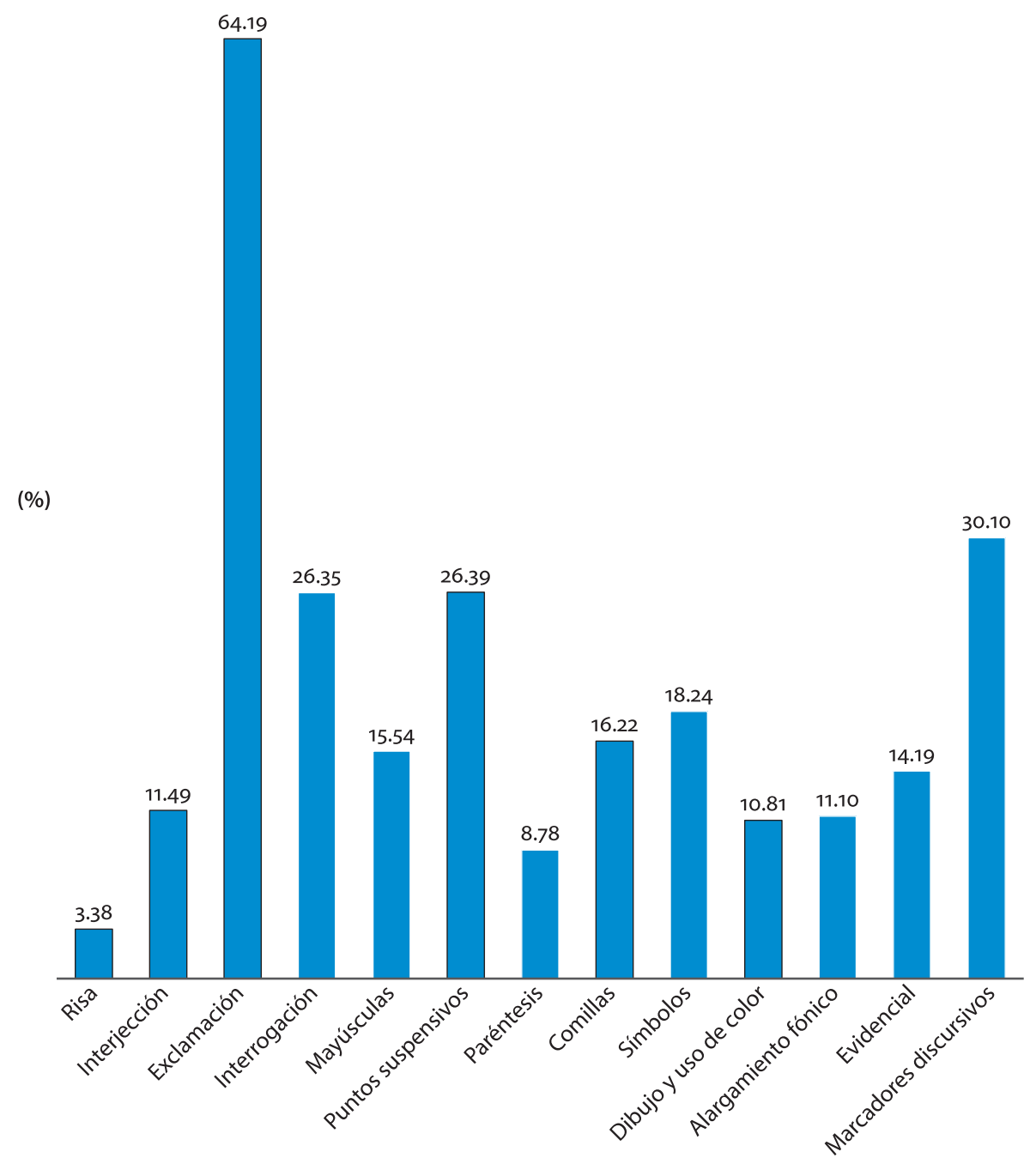

Figura 5. Tipología y porcentajes de marcas humorísticas en las narraciones de 10 años 
(\%)

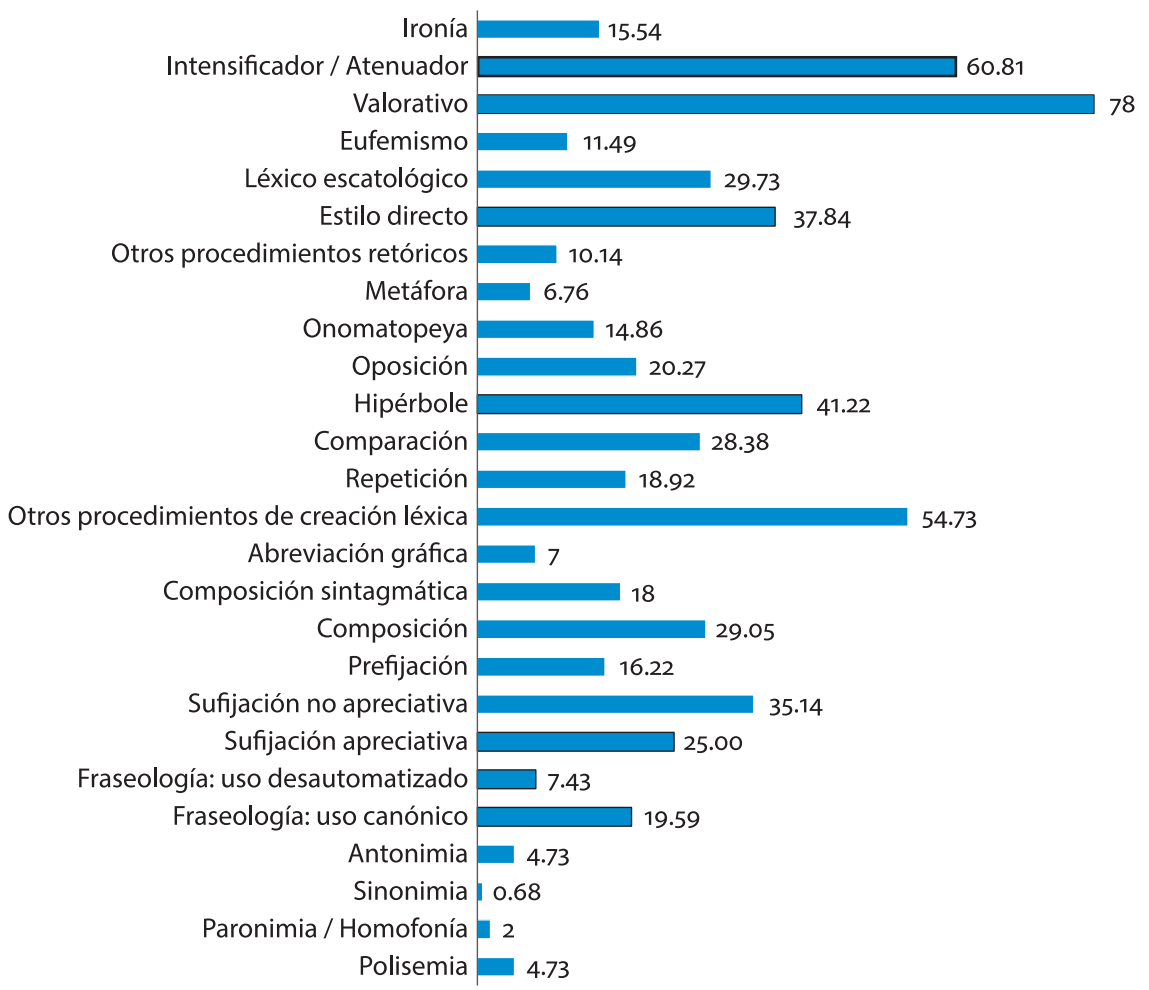

Figura 6. Tipología y porcentajes de indicadores humorísticos en las narraciones de 10 años

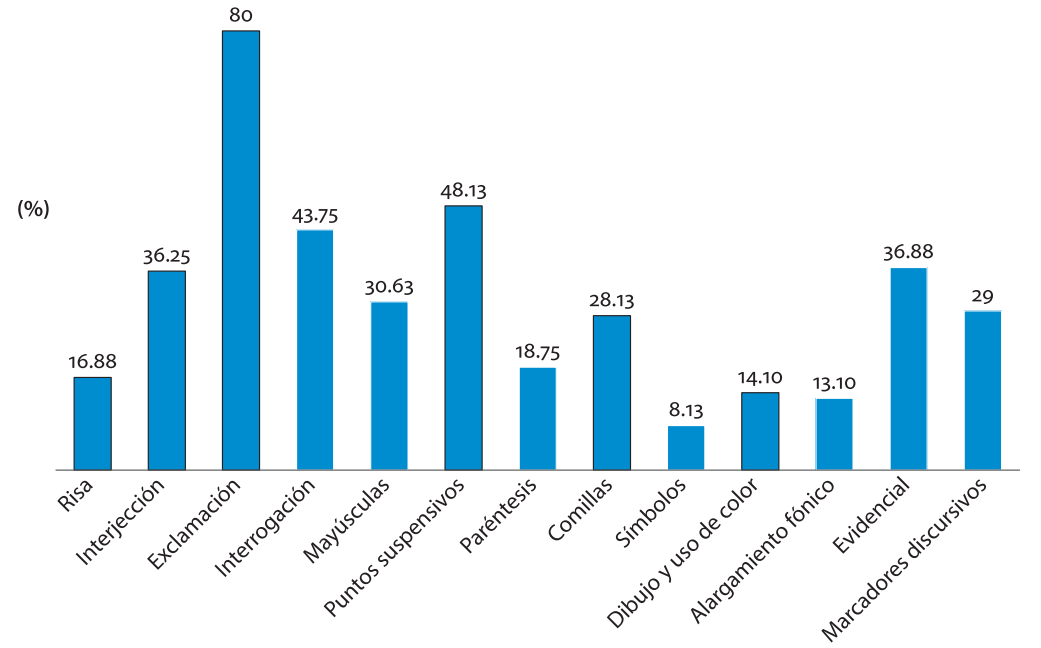

Figura 7. Tipología y porcentajes de marcas humorísticas en las narraciones de 12 años 


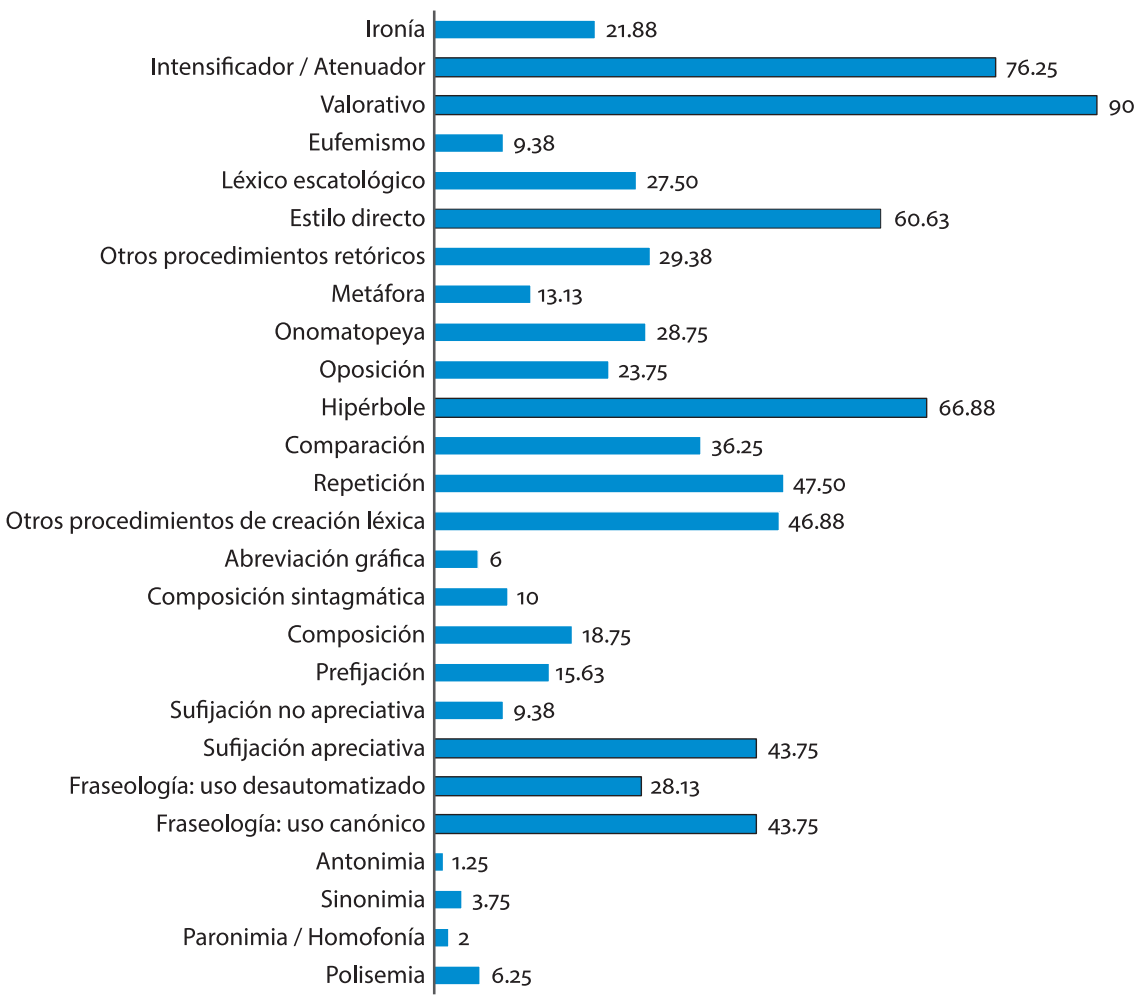

Figura 8. Tipología y porcentajes de indicadores humorísticos en las narraciones de 12 años

Los gráficos presentados muestran que en los tres grupos etarios la marca más frecuente es la exclamación que, además, presenta una evidente evolución en su uso desde el $30,71 \%$ en el corpus de 8 años hasta el $64,19 \%$ a los 10 y el $80 \%$ a los 12 años. Por otro lado, atendiendo a los objetivos de este estudio, se presentan relevantes los datos sobre el empleo de las risas, las comillas o los puntos suspensivos por su evidente relación con el proceso de maduración metalingüística.

En el apartado de indicadores humorísticos destaca la frecuencia de uso del léxico valorativo $\mp 67,14 \%$ en 8 años, $78,38 \%$ en 10 años y $90 \%$ en 12 años; de los intensificadores y atenuantes $\mp 46,43 \%$ en 8 años, $60,81 \%$ en 10 años y $76,25 \%$ en 12 años; o de la hipérbole $\mp 35,71 \%$ en 8 años, $41,22 \%$ en 10 y 66,885 en 12 años. Asimismo, la evolución que experimenta en nuestro corpus la utilización del estilo directo o de la fraseología merece ser destacada, de nuevo, por su marcado carácter metalingüístico. 


\section{Análisis cualitativo}

Mientras que los resultados cuantitativos revelan pautas y tendencias evidentes en cuanto al aumento en la variedad de marcas e indicadores usados desde los 8 hasta los 12 años y una clara evolución hacia las formas lingüísticas más sofisticadas (i.e., lenguaje figurado), una indagación cualitativa de los ejemplos concretos extraídos del corpus se presenta aún más enriquecedora por el carácter ilustrativo que posee de los usos señalados. A continuación, abordaremos un análisis de las diversas marcas e indicadores humorísticos en fragmentos concretos extractados del corpus. Conviene subrayar, de nuevo, que la selección de los aspectos lingüísticos para este análisis cualitativo ha sido determinada, por un lado, por el factor de frecuencia de uso y, por el otro, por la evidencia en la evolución de dichos aspectos a lo largo de las edades estudiadas.

En esta línea, de acuerdo con nuestros datos, las marcas más empleadas, como se presumía, son las relativas a aspectos tipográficos, como las exclamaciones, los puntos suspensivos, las interjecciones y las comillas. Mención especial merece la risa, pues, aunque no es muy frecuente, se trata de un procedimiento habitualmente relacionado con el humor. Como veremos más abajo, a menudo se emplea para evaluar que la historia que se cuenta es humorística. Por otro lado, las narraciones contienen diversos dibujos que, pese a no ser especialmente frecuentes cuantitativamente hablando, manifiestan el proceso evolutivo en el que los informantes se hallan inmersos.

A continuación, en la Tabla 3, se resumen los porcentajes para 12, 10 y 8 años:

Tabla 3. Porcentajes de marcas humorísticas

\begin{tabular}{lccc}
\hline Marca humorística & $\mathbf{1 2}$ años & $\mathbf{1 0}$ años & $\mathbf{8}$ años \\
\hline Exclamaciones & 80 & 64,19 & 30,71 \\
Puntos suspensivos & 48,13 & 26,35 & 6,43 \\
Interjecciones & 36,25 & 11,49 & 12,14 \\
Comillas & 28,13 & 16,22 & 0,71 \\
Risas & 16,88 & 3,38 & 5,71 \\
Dibujos y uso de color & 14,1 & 10,81 & 17,5 \\
\hline
\end{tabular}

En cuanto a los indicadores, destacan los términos valorativos, los intensificadores y atenuantes, la hipérbole, el estilo directo y la sufijación apreciativa. Asimismo, es llamativa la evolución que experimenta el empleo de fraseología, tanto en su uso canónico como desautomatizado. La Tabla 4 refleja estos datos en términos porcentuales: 
Tabla 4. Porcentajes de indicadores humorísticos

\begin{tabular}{lccc}
\hline Indicador humorístico & $\mathbf{1 2}$ años & 10 años & $\mathbf{8}$ años \\
\hline Valorativos & 90 & 78,38 & 94 \\
Intensificadores/atenuantes & 76,25 & 60,81 & 46,43 \\
Hipérbole & 66,88 & 41,22 & 35,71 \\
Estilo directo & 60,63 & 37,84 & 14,29 \\
Sufijación apreciativa & 43,75 & 25 & 26,43 \\
Fraseología: uso canónico & 43,75 & 19,59 & 4,29 \\
Fraseología: uso desautomatizado & 28,13 & 7,43 & 2,86 \\
\hline
\end{tabular}

Dada la amplia gama de marcas e indicadores encontrados, seleccionamos para nuestro análisis los diversos signos tipográficos encontrados, las risas y los dibujos, por un lado; y los términos valorativos, la hipérbole y el estilo directo, por el otro. Trabajos previos se han referido al empleo de elementos valorativos, atenuantes e intensificadores en estas narraciones humorísticas (Martínez Egido 2017), al uso de figuras retóricas (Marimón Llorca 2017) y a la fraseología (Timofeeva-Timofeev 2016).

\subsection{Las marcas humorísticas}

En primer lugar, abordaremos un sucinto análisis de los ejemplos extraídos de nuestro corpus de las marcas humorísticas seleccionadas. Nótese que en todos los ejemplos se preserva la ortografía original.

\subsubsection{Las exclamaciones}

La exclamación es uno de los recursos gráficos que más emplean los niños y niñas. Como ya hemos mencionado, frente al 30,71\% de 8 años, los niños y niñas de 10 años la usan en el $64,19 \%$ de los casos y los de 12 , en el $80 \%$ de las narraciones. El uso de la exclamación anticipa la sorpresa, lo divertido y, por tanto, la incongruencia de la situación humorística que se está describiendo. Asimismo, una utilización adecuada de los signos de exclamación refleja el nivel de conciencia metalingüística, y muy especialmente, de la metatextual. De hecho, observamos cómo en las producciones humorísticas de 8 años las exclamaciones están ligadas a esa 'oralidad' asociada a la inmadurez metatextual (vid. 2.2.) y se utilizan a menudo solo para enmarcar las incongruencias fónico-gráficas propias de una actuación más epipragmática (Ejemplos (1) y (2)). En cambio, detectamos una evolución cualitativa en el uso de estos elementos en las dos franjas etarias posteriores y vemos que los niños y niñas de 12 años ya los dominan con evidente 
soltura y son capaces de emplearlos como verdaderas marcas humorísticas para manifestar lo sorpresivo, extraño o incongruente (Ejemplos (3)-(7)):

(1) ¡Un fifiti totata ñiñitu! que así es como llaman los marcianos al intercambio escolar

$\left(8,14-15, \mathrm{IO}_{24}\right)$

(2) Y así fue viajamos hasta ¡Mumiti Tetete Jolaun! que así es como llaman los marcianos a su planeta

$\left(8,14-15, \mathrm{IO}_{24}\right)$

(3) Bueno, en marte sono una sirena, jla sirena del colegio! Ya era hora de ver todo: mis profesores, mis compañeros y mis asignaturas

$\left(10,12-13 \mathrm{IO}_{32}\right)$

(4) Se me da bien nadar. ¡Pero es una piscina de mocos de piraña acuosos! Pero si me dejo perder me "cortan la cabeza", así que lo intentaré

$\left(10,12-13 \mathrm{SA}_{2}\right)$

(5) Yo era un tipo normal, vivía en un pueblo normal, y tenía una vida normal. Hasta que un día, cuando me desperté... iiiera de dia!!! $\quad(12,14-15$ Bo1)

(6) y al día siguiente cuando me desperté, estaba en casa, no era un bicho peludo, era una persona, conseguí volver !!!!!! (dibujo, carita sonriente) (12, 14-15Mo5)

(7) ¡Soy una mariquita! (es el título de la redacción)

$(12,14-15 \mathrm{IA} 27)$

De este modo, los signos de exclamación se convierten en una marca que evidencia la apreciación del humor que hacen los niños en sus producciones humorísticas (Ruiz-Gurillo 2017a). Así, en el Ejemplo (8) el informante la emplea repetidamente para mostrar la incongruencia de su conversión en hormiga y cómo aprecia que la situación es divertida:

(8) Cuando fui a mirarme en un espejo de repente me di cuenta que me ¡había convertido en una hormiga!

$\left(12,14-15 \mathrm{IO}_{40}\right)$

Pero también cuando reproduce una conversación con un alienígena en (9):

(9) Alien: Tranquilos yo os llevaré a mi planeta jel planeta Marte! . (12, 14-15 $\mathrm{IO}_{40}$ )

\subsubsection{Las interjecciones}

Las interjecciones se emplean en un $12,14 \%$ de los casos en 8 años. Su uso no aumenta en 10 años $(11,49 \%)$, mientras que se manifiesta una frecuencia más alta en 12 años $(36,25 \%)$. Es obvio que esta marca se relaciona estrechamente con la exclamación y que constituye un recurso empleado por los niños y niñas para mostrar sorpresa y anticiparse a la incongruencia de la situación humorística, como evidencian los siguientes Ejemplos ((10)-(12)):

(10) ya estoy en clase ¡dios!!!! Los profes super feos

$\left(8,14-15 \mathrm{SA}_{14}\right)$ 
(11) A todo le digo huy uy uy uy. Porque es como si me hablaran en chino no entiendo nada $(10,12-13$ BA11)

(12) En clase estábamos todos dormidos cuando de repente escuchamos ¡Ttttrrrr!

$$
\left(12,14-15 \mathrm{MO}_{2}\right)
$$

\subsubsection{Los puntos suspensivos}

Otra de las marcas gráficas más empleadas es la de los puntos suspensivos. Está presente en un escaso $6,43 \%$ a los 8 años, incrementa su uso en 10 años $(26,35 \%)$ y dobla su empleo en 12 años $(48,13 \%)$. Es habitual que los puntos suspensivos anticipen la incongruencia que observan los niños y niñas en su nueva situación, como ocurre en los Ejemplos (13) y (14) de 8 y 12 años:

(13) La comida $\mathrm{m} \mathrm{m} \mathrm{m}$ que hambre pero... iiiihA!!!! Que es esto no me lo creo eso es mosquito a la plancha y ratas

$(8,14-15 \mathrm{SA} 14)$

(14) De repente estaba contemplando mi ciudad y... ¡choff! Me quedé pegada a un cristal

$(12,14-15 \mathrm{MA} 8)$

En otros casos, los puntos suspensivos funcionan como elemento enumerativo, tal y como funcionarían en textos no humorísticos (15):

(15) Cuando me monté en un cohete para ir a Marte habían personas de todo tipo: chinos, ingleses...

$(10,12-13$, SA16)

\subsubsection{Las comillas}

Las comillas reflejan la conciencia metalingüística del niño, pues su uso adecuado evidencia que se ha adquirido un control metapragmático de la situación comunicativa y el manejo metatextual es alto. Por ello, se observa un incremento progresivo en las franjas superiores. Frente al escaso $0,71 \%$ de 8 años, las comillas son usadas por un $16,22 \%$ de los informantes de 10 años y por un $28,13 \%$ de los de 12 años. Se emplean para mencionar lo dicho por alguien, como ocurre con el estilo directo, si bien su uso más frecuente corresponde a la mención de palabras o expresiones. Así lo vemos en (16) donde, pese a imitar el estilo directo de los nuevos amigos del informante, se convierte en una marca del nuevo lenguaje inventado:

(16) los amigos era imposible hablar con ellos les voy a imitar "СНОNCHON WACHI CHU CHO SENSA TONI"

$(8,14-15$ SA14)

En otras ocasiones sirve para mencionar a algunos personajes de la historia, como en (17): 
(17) Yo tenía miedo de subir pero mis compañeros "Silvia" y "Daniela" me ayudaron

$(10,12-13, \mathrm{SA1} 6)$

O para marcar ciertas palabras o expresiones de la historia humorística, en (18):

(18) era gracioso porque yo conocía el corte inglés pero el mosca inglés entré para ver lo que había y vi mogolllón de ropa super "xula” y molona y me la compré como había tirado la ropa que no me venía tenía que llevar algo de ropa "para no ir en pelotas".

$(12,14-15 \mathrm{BA} 6)$

Para los niños y niñas de 12 años, las comillas constituyen un recurso gráfico muy útil en el estilo directo, en (19):

(19) No, en serio ¿quién eres? (Nadie) pues "Nadie", cállate” mientras cuenta la historia.

$(12,14-15$ Bo1 $)$

Asimismo, las comillas anticipan el sentido humorístico del texto, como ocurre en (20) donde la palabra entrecomillada, "pequeña" prepara para la incongruencia de la historia:

(20) Me desperté con una sensación ligeramente "pequeña”. Miré a mi alrededor, lo veía todo como... como... ¡como si fuera un insecto!

$(12,14-15 \mathrm{IA} 27)$

\subsubsection{Las risas}

Como mencionábamos más arriba, el empleo de risas no es cuantitativamente representativo en el corpus. Sin embargo, se hace necesario observar cómo se emplea esta marca comúnmente asociada al humor. Aunque la marca es escasa en las narraciones de 8 años $(5,71 \%)$, se mantiene su uso incipiente en 10 años $(3,38 \%)$ y aumenta en 12 años $(16,88 \%)$, lo que evidencia una mayor conciencia metapragmática sobre el recurso.

Así, en algunas narraciones de 10 años, con la risa y la expresión implicada ("se rieron en mi cara") se evalúa la historia contada como humorística:

(21) [...] los alumnos ivamos con trajes espaciales. Resulta que no necesitabamos los trajes espaciales y un alum[n]o marciano me abrió la capsula y yo como una tonta haciendo como si me ahogaba, al cabo de unos minutos me dí cuenta de que en marte podia respirar. Los marcianos se rieron en mi cara [...]

$(10,12-13 \mathrm{SA} 9)$

Por otra parte, la risa, asociada a una mayor competencia humorística de los niños y niñas de 12 años, facilita el uso de textos humorísticos breves en sus historias, como los chistes o las adivinanzas. En el Ejemplo (22) el niño reproduce el texto humorístico por excelencia, un chiste, y las risas manifiestan el efecto que causa en sus destinatarios: 
(22) Izan: dice Picachu pica pica dice otro pues ráscate

Manueh: jajajajajaja qué risa por dios

$(12,14-15$ Ao1 $)$

Como veíamos en el Ejemplo (22), la risa marca el efecto del chiste. Por otra parte, el Ejemplo (23) demuestra un mayor nivel madurativo, pues ya no se conecta con el empleo de chistes o bromas, sino con otros comentarios que pueden resultar jocosos para alguno de los protagonistas. Así, la risa manifiesta el efecto que causa en uno de los protagonistas de la historia el comentario de la niña:

(23) - Muchísimas gracias pero por favor no me comas ni me hagas daño es que soy nuevo en el mundo de los bichos

- Por supuesto ja ja ja ja, vamos rápido es que va a oscurecer $(12,14-15$ SA27)

\subsubsection{El empleo de dibujos}

Como ocurría con la marca de la risa, el empleo de dibujos no es cuantitativamente representativo ( 8 años, 14,1 \%; 10 años, 10,81\%; 12 años 17,5\%). Sin embargo, los niños y las niñas ilustran sus historias con dibujos que ayudan a comprender al potencial lector la situación humorística. Con esta marca nos referimos en primer lugar, a los dibujos propiamente dichos, como ilustran los siguientes Ejemplos (24) y (25):

$(8,14-15$, AA45)

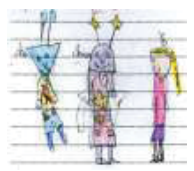

(25)

$(12,14-15 \mathrm{AA} 10)$
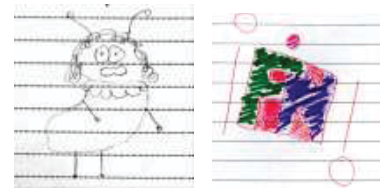

En segundo lugar, esta marca también se refiere al empleo de pictogramas. Son bastante habituales en las narraciones de 8 y 10 años, en las cuales los informantes han escrito sobre su experiencia marciana. En este caso, el hecho de enfrentarse a una nueva realidad genera idiomas inventados (Ruiz-Gurillo 2017a) que a menudo se expresan con pictogramas. Estos sirven para simbolizar la nueva lengua marciana y con frecuencia se parecen a la lengua inicial del niño:

(26) Me adopto una familia muy buena tenían tres hijos muy divertidos y me cuidaron muy bien siempre jugaba con mis amigos marcianos y me comunicaba con las letras

$(8,14-15$, AA45) 
Otras veces los pictogramas aluden a la incongruencia del nuevo idioma marciano, como en (27):

(27) En clase de lengua nos an enseñado su idioma, el criptoniano. Las letras son

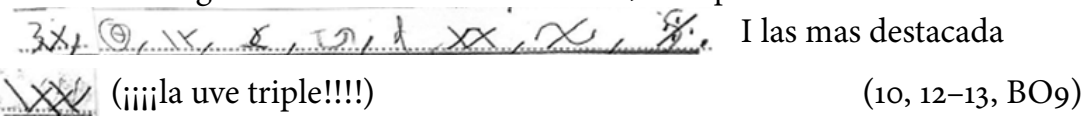

\subsection{Los indicadores humorísticos}

En relación con los indicadores humorísticos, hemos constatado que su empleo también va estrechamente vinculado al proceso de maduración humorística y metalingüística, tal y como revelan los datos cuantitativos. Una indagación cualitativa, a su vez, revela otras consideraciones interesantes.

\subsubsection{Los términos valorativos}

Los niños y niñas están aprendiendo a usar tanto la adjetivación como otros términos valorativos. Muchos de ellos sirven simplemente para calificar los sentimientos, las emociones o los compañeros que encuentran en su viaje. De todos estos términos interesan especialmente los que se infieren de manera inversa a lo que manifiestan, es decir, aquellos que han de interpretarse como indicadores humorísticos. Estos términos valorativos se relacionan concretamente con el uso prototípico de la ironía. Según los datos, en todas las franjas se emplea este indicador de una manera muy significativa ( 8 años, $94 \%$; 10 años, $78,38 \%$; 12 años, 90\%). Lo ilustramos con algunos ejemplos que pueden ampliarse con lo expuesto en Martínez Egido (2017):

(28) En la clase tengo 28 compañeros. Algunos son tontillos y otros son muy listos. Los mejores son Daniel Gómez, Keisy y Laura

$\left(8,14-15 \mathrm{IO}_{31}\right)$

(29) Mis compañeros son muy feos tiene solo dos dientes y cuatro pelos en la cabeza son de color verde y las chicas son de color rojo los ojos son feisimos parecen de serpiente y las orejas las tienen en la boca y la boca en las orejas la nariz la tienen de color negro y tienen tres agujeros de respirar el pelo lo tienen de color amarillo y las mujeres de color azul la cabeza la tienen muy gorda.

$\left(10,12-13 \mathrm{IO}_{37}\right)$

(30) Estira para el saltamontes era el maestro de gimnasio que nos hizo saltar tres metros ipara él es facilísimo! .

$(12,14-15 \mathrm{MO} 11)$

\subsubsection{La hipérbole}

Es otro de los indicadores más empleados, si bien su uso aumenta en cada una de las franjas etarias (8 años, $35,71 \%$; 10 años, $41,22 \%$; 12 años, 66,88\%). De hecho, la 
exageración es uno de los recursos que con más frecuencia emplean los niños y niñas en sus narraciones para apreciar que algo es divertido y, por consiguiente, para generar incongruencia (Ruiz-Gurillo 2017b, 225). También Marimón Llorca (2017) señala la abundancia de este indicador en las narraciones humorísticas. Así lo vemos en los siguientes Ejemplos (31)-(33):

(31) Los profes super feos eran así (DIBUJO) super super feos $\left(8,14-15 \mathrm{SA}_{14}\right)$

(32) Cuando me la dieron empecé? Huy huy huy huy esto no me lo enseño ni en tres años $(10,12-13 \mathrm{BA} 11)$

(33) Me levanté y vi que las mantas había aumentado 1.325.135.958 su tamaño. No pude comprobar lo que tarde en salir de la cama. Aproximadamente un día y medio

$(12,14-15 \mathrm{BO} 10)$

\subsubsection{El estilo directo}

Por su parte, el empleo de estilo directo aumenta en cada una de las franjas etarias (8 años, 14,29\%; 10 años, 37,84\%; 12 años, 60,63\%). Aunque se trata de un recurso complejo tanto formal como conceptualmente, permite ilustrar los diálogos de los personajes de la historia, facilita la polifonía, refuerza como un hecho de autoridad lo narrado y, por lo tanto, permite generar numerosas incongruencias en los textos humorísticos de niños y niñas. Es obvia la conexión de este indicador con el desarrollo de la competencia metatextual, de ahí que los datos cuantitativos corroboren la mayor madurez de los informantes de 12 años en este sentido.

En cuanto a los aspectos formales, se observa que los niños de 8 años todavía no dominan las características gráficas del uso del estilo directo, como las comillas. No obstante, se advierte un uso incipiente de algunos elementos gráficos como la coma:

(34) Y le respondió la profe eso no se sabe pero eso da igual $Y$ dijo de nuevo el niño, no da igual ¿y si envías a un niño y le hace algo?

$\left(8,14-15 \mathrm{IA}_{33}\right)$

En cambio, los niños de 10 años manifiestan una mayor conciencia metatextual, es decir, son mucho más conscientes de la necesidad de emplear signos gráficos para expresar el estilo directo. Aunque no siempre se emplean las marcas correctas, sí se observa una intención de usar alguna de las marcas, ya sea las comillas o los dos puntos:

(35) En el patio me decia: ¡Ha guachi cou ti li li do mi china Loma! Yo le dige traduce y me dijo por un traductor ¡Tio me hechao una carla pirula china que se llama lilidocu!”.

$(10,12-13 \mathrm{IO} 18)$

Incluso alguno de los niños de 10 años es capaz de crear toda una secuencia citativa que contiene las marcas gráficas necesarias para ser comprendida: 
(36) Al quinto día de estar ahí mefui de excursión a la luna y la visite entera y estaba echa de queso y yo cogí un trozo y me lo comí, como todos mis compañeros.

- ¡Estaba buenísimo! - dije yo.

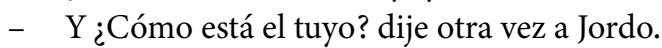

- El mio está pasado de fecha - dijo Jordo

$(10,12-13 \mathrm{IO} 19)$

Por lo que se refiere a los niños y niñas de 12 años, están en proceso de adquirir los aspectos gráficos del estilo directo, aunque algunas redacciones muestran una ausencia de los mismos:

(37) Nosotros al llegar a casa estábamos muertos de hambre así que yo dije voy a coger comida toda mi familia me dijo ¡espera Linda! las mariposas no comen comida humana

$(12,14-15 \mathrm{BA} 5)$

En cambio, otros informantes manifiestan que son conscientes de que deben emplear dichos signos, pese a que no los dominen totalmente:

(38) Yo le contesté

- Vale, vale pero necesito vuestra ayuda-

Me interrumpe:

- Anda corre entra a clase y te presento a mis alumnos

$(12,14-15 \mathrm{IA} 27)$

Por último, cabe señalar que en otros casos el proceso madurativo que experimentan los niños y niñas de 12 años se refleja también en la expresión del estilo directo:

(39) Y después de momento apareció un ciempiés llamado Pepe y me dijo:

- Hola ¿Estás perdido?

- Sí

Y él me dijo:

- Tengo una casita cerca de aquí

$(12,14-15 \mathrm{SA} 27)$

\section{Conclusiones}

El análisis cuantitativo y cualitativo llevado a cabo en este estudio nos capacita para formular las siguientes conclusiones en relación con los objetivos que planteábamos en el apartado 3. Nuestros informantes se encuentran en un periodo de cambios relevantes en relación con su competencia humorística verbal. Dichos cambios van asociados, como es lógico, a su creciente pericia metalingüística que los faculta para un uso cada vez más hábil de diversos procedimientos lingüísticos generadores del humor. De acuerdo con nuestros datos, las principales marcas e indicadores humorísticos que aparecen en las narraciones escritas de nuestro corpus se resumen en la Tabla 5 . 
Tabla 5. Tipología de marcas e indicadores humorísticos en narraciones escritas: 8-12 años

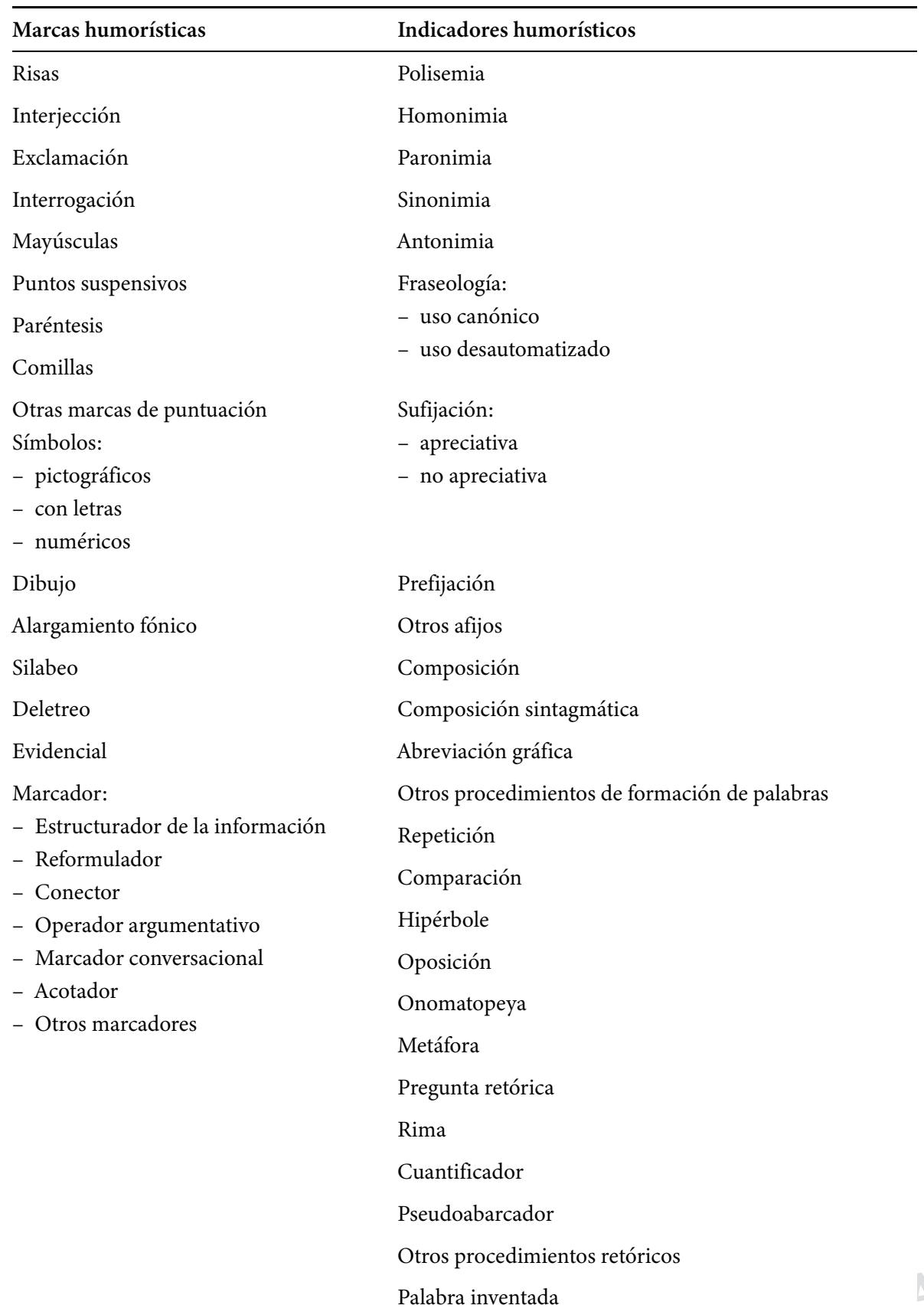


Tabla 5. (continuado)

\begin{tabular}{ll}
\hline Marcas humorísticas & Indicadores humorísticos \\
\hline & Cambio de código \\
& Estilo directo \\
& Léxico escatológico \\
& Eufemismo \\
& Valorativos (positivo - negativo) \\
& Intensificador \\
& Atenuador \\
& Ironía \\
& Variación diasistémica: \\
& - Cambio de registro \\
& - Cambio de dialecto \\
& - Cambio de sociolecto \\
& - Cambio de variedad histórica \\
\hline
\end{tabular}

La clasificación presentada ha constituido la base para la elaboración de un sistema de etiquetado del corpus CHILDHUM que aúna los ejemplos de producciones humorísticas escritas de niños y niñas procedentes de diversos puntos de España. De este modo, ofrecemos una herramienta innovadora y única en el panorama investigador actual para el español, que proveerá material empírico para investigaciones psicolingüísticas de amplio espectro, como la adquisición de las habilidades metalingüísticas, estudio de pautas de la producción escrita, el desarrollo psicosocial, la formación de los estilos de humor y muchas otras.

La evolución que experimenta el uso de las marcas e indicadores - tanto en términos cuantitativos como cualitativos - a lo largo de las tres franjas etarias analizadas, ofrece evidencias claras sobre la marcha del proceso madurativo. Así, observamos que la producción escrita de enunciados humorísticos requiere un alto grado de conciencia metapragmática y metatextual que se manifiestan de manera ciertamente heterogénea a los 8,10 y 12 años de edad. Si bien los acercamientos psicológicos al tema hablan de una alta capacidad metapragmática a partir de los 6 años de edad, nuestros datos confirman que los escolares de 8 años aún presentan un elevado grado de usos epipragmáticos, y su control metatextual es todavía deficiente. Por este motivo, sus producciones escritas presentan abundantes rasgos de oralidad y carecen de elaboración discursiva propia de la modalidad escrita. Ello se refleja en una utilización exigua de marcadores discursivos o de marcas tipográficas como las comillas. El progreso que se manifiesta en relación con estos aspectos a través de las otras dos franjas etarias actúa como un claro 
índice del proceso de maduración metatextual que, a la edad de 12 años, ya se caracteriza por un manejo hábil de las diversas variables de la estructura textual.

En definitiva, en este trabajo se pone de manifiesto el valor de las investigaciones lingüísticas basadas en datos empíricos - como la que presentamos aquí desde el corpus CHILDHUM - pues permiten complementar los hallazgos provenientes de la psicología, hecho que garantiza la creación de tan necesarias sinergias interdisciplinares en el ámbito del estudio del humor verbal infantil.

\section{Información sobre financiación}

Este trabajo forma parte de la investigación llevada a cabo en el marco de los siguientes proyectos de investigación financiados por diversos organismos nacionales y autonómicos: Metapragmática del humor infantil: adquisición, perspectiva de género y aplicaciones (GRE14-19, Universidad de Alicante), La formación de la conciencia figurativa en la etapa de Educación Primaria: el humor y la fraseología (FFI2016-76047-P, AEI/FEDER, UE), El humor interaccional en español. Géneros orales, escritos y tecnológicos (PID2019-104980GB-Ioo, MICIU, AEI) y Humor de género: observatorio de la identidad de mujeres y hombres a través del humor (PROMETEO/2016/052, Generalitat Valenciana).

\section{Referencias}

Alvarado Ortega, M. Belén. 2016a. "Descortesía y humor fallido en conversaciones entre hombres y mujeres." SOPRAG, 4.2: 243-267.

Alvarado Ortega, M. Belén. 2016b. "Variability, adaptability and negotiability in conversational humor: A question of gender." En Metapragmatics of Humor: Current Research Trends, ed. por Leonor Ruiz-Gurillo, 192-214. IVITRAA Research in Linguistics and Literature, John Benjamins. https://doi.org/10.1075/ivitra.14.10alv

Attardo, Salvatore. 2017. "Humor in Language." En Oxford Research Encyclopedia of Linguistics. Ed. recuperada el 22 de enero de 2019 de http://oxfordre.com/linguistics/view/10.1093 /acrefore/9780199384655.001.0001/acrefore-9780199384655-e-342. https://doi.org/10.1093/acrefore/9780199384655.013.342

Burgers, Christian, y Margot van Mulken. 2017. "Humor Markers." En The Routledge handbook of language and humor, ed. por Salvatore Attardo, 385-399. London, New York: Routledge. https://doi.org/10.4324/9781315731162-27

Collins, Anna, Elaine Lockton, y Catherine Adams. 2014. "Metapragmatic explicitation ability in children with typical language development: Development and validation of a novel clinical assessment." Journal of Communication Disorders, 52: 31-43. https://doi.org/10.1016/j.jcomdis.2014.07.001

Crespo, Nina, y Pedro Alfaro. 2009. "La conciencia metapragmática en la edad escolar." Boletin de lingüistica 21:32. http://www.scielo.org.ve/scielo.php?script=sci_arttext\&pid=So798$97092009000200002 \& \operatorname{lng}=e s \& n r m=i s o$ 
Crespo, Nina, y Carola Alvarado. 2010. "Conciencia metapragmática y memoria operativa en niños escolares." Literatura y Lingüística, 21: 93-108.

Crespo, Nina, Ricardo Benítez, y Lorena Pérez. 2010. "Conciencia metapragmática y la habilidad para producir narraciones escritas." Revista Signos, 43 (73): 179-209. https://doi.org/10.4067/S0718-09342010000200001

Cunningham, Jennifer. 2005. "Children's humor." En Children's play, ed. por W. George Scarlett, Sophie Naudeau, Dorothy Salonius-Pasternak, e Iris Ponte. SAGE publications.

Doherty, Martin, y Josef Perner. 1998. "Metalinguistic awareness and Theory of Mind: just two words for the same thing?" Cognitive Development, 13: 279-305. https://doi.org/10.1016/So885-2014(98)90012-0

Forabosco, Giovannantonio. 2008. "Is the Concept of Incongruity Still a Useful Construct for the Advancement of Humor Research?" Lodz Papers in Pragmatics, 4 (1): 45-62. https://doi.org/10.2478/v10016-008-0003-5

Galindo Merino, M. del Mar. 2017. "La identidad de género a través del humor en niños y niñas de 10 años." Círculo de Lingüística Aplicada a la Comunicación, 70: 99-118. https://doi.org/10.5209/CLAC.56319

Gironzetti, Elisa. 2017. "Prosodic and multimodal markers of humor." En The Routledge handbook of language and humor, ed. por Salvatore Attardo, 400-413. London, New York: Routledge. https://doi.org/10.4324/9781315731162-28

Gombert, Jean E. 1992. Metalinguistic development. New York: Wheatsheaf.

Hoicka, Elena y Nameera Akhtar. 2012. "Early humour production." British Journal of Developmental Psichology, 30 (4): 586-603. https://doi.org/10.1111/j.2044-835X.2011.02075

Lyon, Catherine. 2006. "Humour and the young child. A review of the research literature." Televizion, 19: 4-9.

Marimón Llorca, Carmen. 2017. "Estrategias para construir humor. Las figuras retóricas en relatos humorísticos de niños de 8 y 12 años." Círculo de Lingüística Aplicada a la Comunicación, 70: 61-8o. https://doi.org/10.5209/CLAC.56317

Martin, Rod A. 2007. The Psychology of Humor: An Integrative Approach. Burlington: Elsevier Academic Press. https://doi.org/10.1016/B978-012372564-6/50024-1

Martin, Rod A. 2014. Review of the book What Are You Laughing at? A Comprehensive Guide to the Comedic Event. Europe's Journal of Psychology, por D. O'Shannon, 10 (3): 582-585. https://doi.org/10.5964/ejop.v10i3.823

Martin, Rod A. 2016. "Sense of humor." En Positive psychological assessment, 2nd ed., ed. por S. J. López, 350-353. American Psychological Association.

Martínez Egido, José Joaquín. 2016. “Humor y noticias económicas y financieras en la prensa española.” Lingüística Española Actual, 38 (1): 161-185.

Martínez Egido, José Joaquín. 2017. "La expresión de la subjetividad en el humor infantil: elementos valorativos, atenuadores e intensificadores." Círculo de Lingüística Aplicada a la Comunicación, 70: 81-98. https://doi.org/10.5209/CLAC.56318

McGhee, Paul E. 1979. Humor: Its Origin and Development. New York: W. H. Freeman.

McGhee, Paul E. 2002. Understanding and Promoting the Development of Children's Humor. Dubuque, IA: Kendall Hunt Publishing.

Meany, Michael M., Tom Clark y Liisi Laineste. 2014. "Comedy, Creativity, and Culture: A Metamodern Perspective." The International Journal of Literary Humanities, 11(4): 1-15. https://doi.org/10.18848/2327-7912/CGP/v11io4/43909 
Myhill, Debra. 2012. "The ordeal of deliberate choice: metalinguistic development in secondary writers." En Past, Present, and Future Contributions of Cognitive Writing Research to Cognitive Psychology, ed. por Virginia Wise Berninger, 247-274. Taylor y Francis Group.

O'Shannon, Dan. 2012. What Are You Laughing at? A Comprehensive Guide to the Comedic Event. Bloomsbury Academic.

Piaget, Jean. 1972. The psychology of the child. New York: Basic Books.

Piaget, Jean. 1987. El lenguaje y el pensamiento del niño pequeño. Barcelona: Paidós.

Ruiz-Gurillo, Leonor. 2012. La lingüistica del humor en español. Madrid: Arco Libros.

Ruiz-Gurillo, Leonor. 2014. "Infiriendo el humor. Un modelo de análisis para el español." Círculo de Lingüística Aplicada a la Comunicación, 59: 148-162. http://revistas.ucm.es /index.php/CLAC/article/view/46712/43844

Ruiz-Gurillo, Leonor. 2017a. "Idiomas inventados en las narraciones humorísticas de niños de 8 a 12 años." Círculo de Lingüística Aplicada a la Comunicación, 70: 43-59. https://doi.org/10.5209/CLAC.56316

Ruiz-Gurillo, Leonor. 2017b. "Humor production in children's narratives in Spanish." Calidoscópio, 15 (2): 222-231. https://doi.org/10.4013/cld.2017.152.01

Ruiz-Gurillo, Leonor (ed) 2016. Metapragmatics of humor: Current Research Trends. John Benjamins. https://doi.org/10.1075/ivitra.14

Santamaría Pérez, M. Isabel. 2017. "La expresión del humor infantil a través de la formación de palabras en narraciones escritas." Círculo de Lingüística Aplicada a la Comunicación, 70: 21-42. https://doi.org/10.5209/CLAC.56315

Timofeeva-Timofeev, Larissa. 2014. "El humor verbal en niños de educación primaria: presentación de un estudio." Femenismo/s, 24: 195-219. https://doi.org/10.14198/fem.2014.24.09

Timofeeva-Timofeev, Larissa. 2016. "Children Using Phraseology for Humorous Purposes: The Case of 9-to-10-year-olds." En Metapragmatics of Humor: Current Research Trends, ed. por Leonor Ruiz-Gurillo, 275-300. IVITRAA Research in Linguistics and Literature, John Benjamins. https://doi.org/10.1075/ivitra.14.14tim

Timofeeva-Timofeev, Larissa. 2017. "Metapragmática del humor infantil." Círculo de Lingüística Aplicada a la Comunicación, 70: 5-19. https://doi.org/10.5209/CLAC.56314

Timofeeva-Timofeev, Larissa y Leonor Ruiz-Gurillo. 2018. "Fraseología y humor: de semántica y pragmática." En Lenguaje figurado y competencia interlingüística (I), ed. por Antonio Pamies, Alexandra Magdalena, e Isabel María Balsas, 151-163. Granada: Comares.

Verschueren, Jef. 2000. "Notes on the role of metapragmatic awareness in language use." Pragmatics, 10 (4): 439-456. https://doi.org/10.1075/prag.10.4.02ver

\section{Humor markers and indicators in 8, 10 and 12-years-olds' stories written in Spanish: A typological approach}

\section{Abstract}

This paper presents a typology of humor markers and indicators (Ruiz-Gurillo 2012, 78-86) which acts as an empirical 'underpinning' for children's verbal humor research. This typology is 
based on the analysis of 448 humorous stories written by schoolchildren aged 8,10 and 12 from 5 educational centers located in the Spanish province of Alicante (Timofeeva-Timofeev 2017). Furthermore, this supports the tagging system for the corpus CHILDHUM - currently under construction - which is comprised of these and other stories written by children from different parts of Spain. The observation, within the corpus, of how the use of humor markers and indicators evolves throughout the age bands under examination, brings to light some patterns of the humor competence and the metalinguistic development. Such empirical data are relevant since they are not completely accessible from the psychological perspective.

Keywords: 8-12 years-old children, humor markers and indicators, humor competence, metalinguistic development

\section{Dirección para la correspondencia}

Larissa Timofeeva-Timofeev

Dpto. de Filología Española, Lingüística General y Teoría de la Literatura

Universidad de Alicante

Campus de San Vicente del Raspeig

Apdo. 99

E-03080 Alicante

España

Timofeeva@ua.es

\section{Notas biográficas}

Larissa Timofeeva-Timofeev es profesora titular de Lingüística en la Universidad de Alicante. Su investigación gira en torno a la fraseología, los estudios de la ironía y el humor, la adquisición del lenguaje, la lingüística aplicada a la enseñanza de lenguas y la traductología. Es miembro de los grupos de investigación GRIALE y ACQUA. Ha dirigido 2 proyectos de investigación sobre la formación de la competencia humorística durante la etapa de educación primaria. Los resultados de sus investigaciones se recogen en cerca de 60 publicaciones en editoriales y revistas de especialidad. Asimismo, ha ejercido diversas labores de gestión académica y de divulgación.

Leonor Ruiz-Gurillo es catedrática de Lengua Española en la Universidad de Alicante. Ha centrado su investigación en diversos temas de la fraseología española, español coloquial, pragmática, ironía y humor. Entre sus trabajos destacan los libros Aspectos de fraseología teórica española (Valencia, Universidad, 1997), Hechos pragmáticos del español (Alicante, Universidad, 2006), La lingüística del humor en español (Madrid, Arco/Libros, 2012) y Humor de género: del texto a la identidad en español (Madrid, Iberoamericana, 2019). Desde 2002 dirige el grupo de investigación GRIALE que se encarga del análisis pragmático de la ironía y el humor. Ha dirigido 6 proyectos de investigación sobre el humor verbal. Cuenta con más de 100 publicaciones en editoriales y revistas de alto impacto. 